EPJ Web of Conferences 82, 01018 (2015)

DOI: $10.1051 /$ epjconf/20158201018

(C) Owned by the authors, published by EDP Sciences, 2015

\title{
The ways of mass transfer intensification in industrial jet scrubbers
}

\author{
Michael Shilyaev ${ }^{\mathrm{a}}$, Helen Khromova and Svetlana Shirokova \\ Tomsk State University of Architecture and Building, 634003 Tomsk, Russia
}

\begin{abstract}
This paper is devoted to parametrical analysis of model, and is aimed at understanding its possibilities to find the most profitable conditions for the technical processes. These processes should consider the maximal extraction of gas and mechanical admixtures from the flow on the droplets of irrigating liquid and reduce the dimensions of hollow direct-flow jet scrubbers (DFJS) and Venturi scrubbers (VS).
\end{abstract}

The jet scrubbers are widely used in various industries for extraction of target gas components from the vapor-gas flows both for gas cleaning and for extraction of these components as the valuable products of chemical production. In either case, it is important to determine the conditions, under which they can be maximally extracted with less material and energy costs. In the complex simultaneously, it can be challenged to clean the flow from mechanical impurities: dust, which is a product of technological process. This problem is very complex and cannot be solved optimally by the experimental methods. The only effective tool to solve it can be mathematical modeling of such a complex process that adequately describes both hydrodynamics and combined heat and mass transfer, occurring in these devices.

In the current study we perform the parametrical analysis of model [1], aimed at understanding its possibilities to find the most profitable conditions for the technical processes from the point of maximal extraction of gas and mechanical admixtures from the flow on the droplets of irrigating liquid and from the point of reducing the dimensions of devices. Here we will consider the hollow direct-flow jet scrubbers (DFJS) and Venturi scrubbers (VS). As for other device, for instance, the counter-flow jet scrubbers, their optimization can be performed in the similar way.

Calculations for DFJS were carried out for the following basic parameters: working section height $H=12.75 \mathrm{~m}$; irrigation coefficient $q=0.015 \mathrm{~m}^{3} / \mathrm{m}^{3}$; initial diameter of droplets of irrigating liquid $\delta_{k 0}=700 \mu \mathrm{m}$; initial velocity of droplets at nozzle outlet $V_{k 0}=24.5 \mathrm{~m} / \mathrm{s}$; initial temperature of droplets $T_{k 0}=278 \mathrm{~K}$; initial temperature of vapor-gas flow $T_{00}=293 \mathrm{~K}$; initial moisture content $d_{0}=0.02 \mathrm{~kg} / \mathrm{kg}$ of dry air; initial velocity of gas-vapor flow $U_{0}=0.25 \mathrm{~m} / \mathrm{s}$; initial gas content of $\mathrm{SO}_{2} d_{\mathrm{SO}_{2}, 0}=0.2 \mathrm{~kg} / \mathrm{kg}$ of dry air; initial gas content of $\mathrm{CH}_{4} d_{\mathrm{CH}_{4}, 0}=0.2 \mathrm{~kg} / \mathrm{kg}$ of dry air; initial concentration of dust particles $\rho_{0}=0 \mathrm{~kg} / \mathrm{m}^{3}$. As a results of this version of calculation we obtain: extraction efficiency $\eta_{\mathrm{SO}_{2}}=0.51054 ; \eta_{\mathrm{CH}_{4}}=0.0008446$, therefore, we can see that $\mathrm{SO}_{2}$ is absorbed well on water, whereas, methane is not extracted at all. At that, extraction of $\mathrm{SO}_{2}$ until the state of complete thermodynamic equilibrium occurs along almost all height of absorber (curve 1, Fig. 1).

\footnotetext{
${ }^{a}$ Corresponding author: shmi@mail.tomsknet.ru
}

This is an Open Access article distributed under the terms of the Creative Commons Attribution License 4.0, which permits unrestricted use, distribution, and reproduction in any medium, provided the original work is properly cited. 


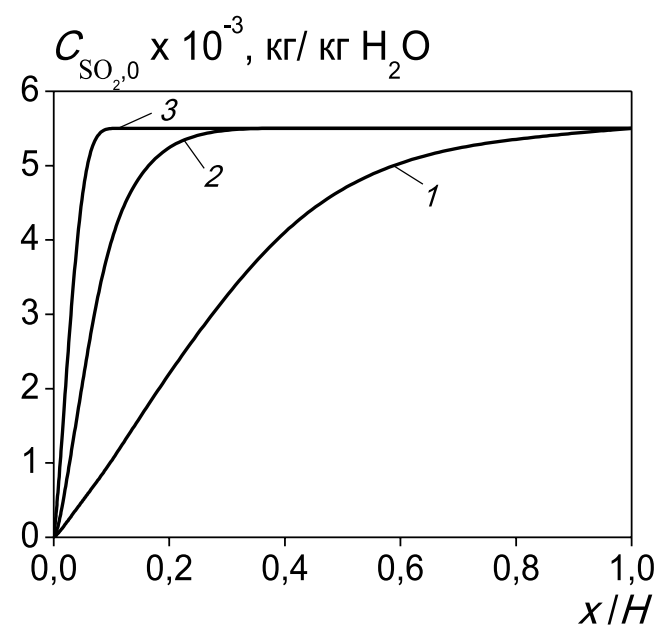

Figure 1. Calculation of $\mathrm{SO}_{2}$ concentration in liquid droplets: $1-\delta_{k 0}=700 \mu \mathrm{m}\left(\eta_{\mathrm{SO}_{2}}=0.51054 ; \eta_{\mathrm{CH}_{4}}=\right.$ $0.0008446) ; 2-\delta_{k 0}=300 \mu \mathrm{m}\left(\eta_{\mathrm{SO}_{2}}=0.51561 ; \eta_{\mathrm{CH}_{4}}=0.00065869\right) ; 3-\delta_{k 0}=150 \mu \mathrm{m}\left(\eta_{\mathrm{SO}_{2}}=0.51557 ; \eta_{\mathrm{CH}_{4}}=\right.$ $0.00083225)$.

The next versions of calculation included changes in some determining parameters relative to the basic ones. Thus, a decrease in the diameter of droplets of dispersed liquid significantly reduces the path of their motion to thermodynamic equilibrium, and the smaller the droplet size, the shorter this path at the same extraction efficiency both for $\mathrm{SO}_{2}$ and $\mathrm{CH}_{4}$ (see Fig. 1).

A change in $V_{k 0}$ from 10 to $24.5 \mathrm{~m} / \mathrm{s}$ did not affect extraction of $\mathrm{SO}_{2}$ and $\mathrm{CH}_{4}$. For $V_{k 0}=10 \mathrm{~m} / \mathrm{s}$, $\eta_{\mathrm{SO}_{2}}=0.51202, \eta_{\mathrm{CH}_{4}}=0.0010669$; for $V_{k 0}=15 \mathrm{~m} / \mathrm{s}, \eta_{\mathrm{SO}_{2}}=0.51173, \eta_{\mathrm{CH}_{4}}=0.00077761$.

A decrease in the initial droplet temperature, an increase in the initial temperature of the gas-vapor flow and a rise of initial moisture content affect significantly the efficiency of gas component extraction. Thus, at a decrease in $T_{k 0}$ from $293 \mathrm{~K}$ to $275 \mathrm{~K}$ we have an increase in $\eta_{\mathrm{SO}_{2}}$ from 0.36737 to 0.53116 and $\eta_{\mathrm{CH}_{4}}$ from 0.00054089 to 0.0010346 ; at an increase in $T_{00}$ from $273 \mathrm{~K}$ to $323 \mathrm{~K}$ we have enlargement of $\eta_{\mathrm{SO}_{2}}$ from 0.49579 to 0.53125 and $\eta_{\mathrm{CH}_{4}}$ from 0.00078618 to 0.00094349 ; increasing moisture content $d_{0}$ from $0.02 \mathrm{~kg} / \mathrm{kg}$ of dry air to $0.1 \mathrm{~kg} / \mathrm{kg}$ of dry air we obtain a rise of $\eta_{\mathrm{SO}_{2}}$ from 0.51054 to 0.52147 and $\eta_{\mathrm{CH}_{4}}$ from 0.0008446 to 0.0015538 . A change in the initial velocity of the gas-vapor flow $U_{0}$ from $0.25 \mathrm{~m} / \mathrm{s}$ to $1 \mathrm{~m} / \mathrm{s}$ do not affect the efficiency of $\mathrm{SO}_{2}$ and $\mathrm{CH}_{4}$ extraction. The influence of a change in the initial concentration of extracted component on extraction efficiency is also weak.

According to previously mentioned, intensity of absorption process in DFJS can be enhanced by a decrease in the temperature of irrigation liquid and an increase in temperature and moisture content of the gas-vapor flow at the inlet. Thus, at $d_{0}=0.5 \mathrm{~kg} / \mathrm{kg}$ of dry air, $T_{k 0}=275 \mathrm{~K}$ and $T_{00}=368 \mathrm{~K}$ and the same other basic parameters, $\eta_{\mathrm{SO}_{2}}=0.65109$ and $\eta_{\mathrm{CH}_{4}}=0.0016055$.

Increasing the irrigation coefficient improves significantly the extraction efficiency of the target component, and this is determined by a more developed surface of the phase contact, deeper gas cooling and lower droplet heating smaller drops, determining higher concentration difference at lower Henry equilibrium coefficient (for lower droplet temperatures).

Heat and mass transfer, $\mathrm{H}_{2} \mathrm{~S}$ absorption and dust catching on water droplets in the Venturi scrubber were calculated. These calculations were carried out at the following parameters, partially corresponding (without flow dustiness) to experimental conditions [2]: length of diffuser of Venturi tube $l=0.2 \mathrm{~m}$, diameter of tube mouth $d_{\Lambda}=0.02 \mathrm{~m}$, diffuser angle $\alpha=6^{\circ}$, irrigation coefficient $q=0.015 \mathrm{~m}^{3} / \mathrm{m}^{3}$, initial velocity of water droplets $V_{k 0}=4 \mathrm{~m} / \mathrm{s}$; velocity of the gas-vapor flow in the tube mouth $U_{0}=80 \mathrm{~m} / \mathrm{s}$, initial temperature of the vapor-gas flow $T_{00}=333 \mathrm{~K}$, initial temperature of droplets 
$T_{k 0}=278 \mathrm{~K}$, initial gas content $\mathrm{H}_{2} \mathrm{~S} d_{\mathrm{H}_{2} \mathrm{~S}, 0}=0.1 \mathrm{~kg} / \mathrm{kg}$ of dry air, size of dust particles $\delta_{0}=0.1 \mu \mathrm{m}$, initial moisture content $d_{0}=0.2 \mathrm{~kg} / \mathrm{kg}$ of dry air, dust concentration at the scrubber inlet was set $\rho_{\text {ч0 }}=1.72 ; 5.0 ; 10.0 ; 15.0 \mathrm{~g} / \mathrm{m}^{3}$, dust density was conditionally set equal to water density. The initial size of droplets was calculated by the known formula for pneumatic liquid spraying of NukiyamaTanasawa, and in this case it was $d_{k 0}=137 \mu \mathrm{m}$. Calculation results are presented in Table:

\begin{tabular}{|l|l|l|l|l|}
\hline \multirow{2}{*}{ Catching efficiency } & \multicolumn{3}{|c|}{ Dust concentration at the inlet, g/m ${ }^{3}$} \\
\cline { 2 - 5 } & 1.72 & 5.0 & 10.0 & 15.0 \\
\hline$\eta_{\mathrm{H}_{2} \mathrm{~S}}$ & 0.073 & 0.073 & 0.075 & 0.093 \\
\hline$\eta_{\mathrm{Y}}$ & 0.529 & 0.282 & 0.196 & 0.165 \\
\hline
\end{tabular}

According to this table, with a rise of dust concentration at the inlet the efficiency of hydrogen sulfide extraction increases, and this occurs due to its additional solving in the condensate on dust particles, whereas, the efficiency of dust catching decreases considerably. The latter is explained by a smaller increase in the size of "formations" (particles with condensate on the surface) in comparison with their initial size at high concentrations, than at low concentrations. This fact should be taken into account, when organizing condensation catching of fine dusts with minimally possible concentrations at device inlets and considering the circumstance that an increase in the degree of absorption extraction of gas component with enlargement of particle concentration in the flow is insignificant in comparison with a decrease in dust catching efficiency. It is desirable to implement absorption on the smaller droplets; this will ensure a significant decrease in device sizes. It is mentioned in [3] that "relatively effective condensation catching... in a hollow scrubber can be achieved at irrigation density not lower than $8.51 / \mathrm{m}^{3}$ ". However, we should note that the choice of irrigation density together with other parameters for some specific conditions could be optimal with the use of our model.

The present work was financially supported by the Federal target of the Russian Ministry of Education and Science Program No. 14.DDD.21.0009.

\section{References}

[1] M.I. Shilyaev, E.M. Khromova Modeling of heat and mass transfer and absorption-condensation dust and gas cleaning in jet scrubbers. Mass Transfer - Advances in Sustainable Energy and Environment Oriented Numerical Modeling (In Tech, Vienna, Austria, 2013)

[2] V.M. Ramm, Absorption of Gases (Khimiya, Moscow, 1976)

[3] G.O. Kutuzov, A.Yu. Valdberg Efficiency of catching of sublimate from electric furnaces, smelting ferroalloys, by hollow scrubbers, J. Ind. and San. Clean. of Gas., 3 (1977) 